\title{
SOCIAL CLASS HABITS OF CONSULTING
}

\author{
BY \\ H. B. KEDWARD* \\ Nottingham
}

This is a survey of social class habits of consulting in a rural general practice situated on the eastern fringe of the Nottinghamshire coalfield in a village which is referred to as Longlands. The practice has almost a monopoly of the 1,500 population, which is in effect a closed medical community, lying a mile away from the main road. There is a wide range of socio-economic groups. There are no industries in the village but many coal miners live there as there are several collieries within a few miles.

This village was suitable for this type of study for several reasons. It was possible for one doctor to arrange to handle virtually all contacts with patients and, as it turned out, he did see everyone during the survey period of 3 months, with the exception of those consulting at one week-end when the doctor attending them made the necessary notes. Coordination of recording methods and diagnostic labelling was reduced to a minimum because almost all the recording was done by one observer. Secondly, almost all the residents were practice patients and there was only one surgery in the village. A small percentage ( 3.5 per cent.) of the population were served by doctors in neighbouring towns. Thirdly, the medical population seemed likely to be stable as only seven people had changed their doctor for reasons other than leaving the district, in the preceding 6 years.

The method was designed to test two hypotheses:

(1) That there is a significant relationship between social class and the frequency of demands made upon the medical services.

(2) That there is a relationship between social class and the kind of demand made.

\section{Method}

The use of prescription form copies is described fully elsewhere (Kedward, 1962).

A census was taken of the population resident in the village on November 1,1959 . The individuals in

- Present address is: The Maudsley Hospital, Beckenham, Kent each household were counted, and their relationship, age, occupation, and place of employment noted. This information was checked against the electoral register and the practice medical record cards.

The census was of households numbered in street order. The social class of each household was assessed on the Hall-Jones scale, by the occupation of the head of the household (Hall and Jones, 1950). In addition to the seven classes, a separate sectionthose with a head of household who worked in or about the coalmine-was formed. There are many references to mining occupational morbidity but as there was no intention of assessing this, individual miners were not separated. Mining households were kept apart because it appeared interesting to look for cultural features and consulting habits and perhaps also to compare with an insular mining population in the other large village of the practice.

The Hall-Jones scale aims at distinguishing between occupations according to their social prestige and offers a rather wider range than the Registrar General's Classification. The following comparisons are suggested with the Registrar General's Classification:

\begin{tabular}{c|c}
\hline Registrar General & Hall-Jones \\
\hline 1 & 1 and 2 \\
2 & 3 and 4 \\
3 & 5 \\
4 & 6 \\
5 & 7 \\
\hline
\end{tabular}

\section{Medical Data}

Each consultation was recorded and the social class was entered from the census sheets. A record was kept of the way each patient consulted, whether by surgery attendance or house-call. In addition, information was sought which most previous general practice morbidity studies had excluded-the indirect 
consultation. Examples of this are the "roadside request", the telephone enquiry, the request through the chemist or the surgery attender who says, "And may I have something for auntie's cold ?". The indirect consultation was thought to be important in a study of social class habits. Logan and Cushion (1958) warned that indirect requests are easily forgotten unless entered immediately. In order to include this material, the requirements were that every consultation should be recorded on a separate sheet. This sheet had to be small-small enough to carry in the pocket-as it might be needed any time of day or night during the 3 months. A prescription form was used or, in the many cases when a prescription was given, a carbon copy of the prescription was taken on which the patient's Hall-Jones class was entered and symbols denoting the type of consultation and disposal. The code included hospital referrals, preventive medicine consultations, occupational disease or injury, contact with a consultant, trivial or unreasonable requests, and night consultations.

Recording began on November 1, 1959, and continued until the end of January, 1960. There was minimal change in the population caused by people leaving the district, new residents, births, and deaths. Patients attending the surgery whose names were not on the census list (i.e. who were not resident on November 1, 1959) were given a Hall-Jones class, and their medical information was recorded and included with the others, as they were considered to replace people leaving the district. No alterations were made in the census list. The period of 3 months had been previously calculated from the results of a pilot survey as being likely to provide the maximum number of patient-doctor contacts which could be handled by the method-about 2,500 .

During the recording period, the carbon copies were arranged chronologically by morning surgery, home visits, and evening surgery and each was given a single-line entry to form the Analysis List. The 2,000 odd lines had the appropriate code entered in columns. This list was useful to extract rapidly such information as the number of hospital referrals and the social class of the patients.

The carbon copies were then re-arranged in households by class and most of the information on consultations was then conveniently available to be examined from the class standpoint. For instance, the first household group of the packet of papers of the mining section might be:

$$
\begin{aligned}
& \text { Allan, Sydney. } 42 \text { years. 3, Well Lane. } \\
& \text { (Morn. surg. Lumbago. 12.11.59) } \\
& \text { " , John, 14-his son. 3, Well Lane. } \\
& \text { (Morn. surg. Nervous tic. 29.11.59) } \\
& \text { " , Elsie, 39-his wife. 3, Well Lane. }
\end{aligned}
$$$$
\text { (Visit. Septic toe. 4.12.59) }
$$

\section{RESULTS}

CEnsus.-Table I gives information about the population of 1,426 "at risk" to the practice, and refers to 96.5 per cent. of people living in the village. The remaining 53 individuals, living in seventeen households, were attended by other doctors.

Demand by Whole Practice.-Table II shows the gross consultations for all patients irrespective of class. The general high level of demand or use of the doctor is apparent. In the short period of 30 months over half the practice population found it: necessary to consult. The average frequency of con-

\begin{tabular}{|c|c|c|}
\hline $\begin{array}{l}\text { Number of Consultations } \\
\text { Ratio (Female : Male) . . } \\
\text { Registered Individuals . . } \\
\text { Average Consultations per Week } \\
\text { Consultations per Week for every 1, } \\
\text { Patients Consulting } \\
\text { Percentage of Patients Consulting } \\
\text { Average No. of Consultations per P } \\
\text { Average No. of Consultations per P }\end{array}$ & 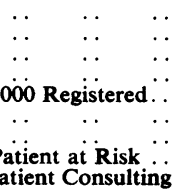 & $\begin{array}{l}2,290 \\
1 \cdot 35: 1 \\
1,426 \\
176 \\
123 \\
765 \\
54 \\
1 \cdot 60 \\
3 \cdot 0\end{array}$ \\
\hline
\end{tabular}
sulting of 1.6 for all patients, with an average of

TABLE II

MEDICAL CONSULTATION FIGURES FOR THE WHOLE

\begin{tabular}{|c|c|c|c|c|c|c|c|c|c|}
\hline \multirow{2}{*}{$\begin{array}{c}\text { Social } \\
\text { Class }\end{array}$} & \multirow{2}{*}{$\begin{array}{l}\text { No. of } \\
\text { Households }\end{array}$} & \multirow{2}{*}{$\begin{array}{c}\text { No. of } \\
\text { Individuals }\end{array}$} & \multirow{2}{*}{$\begin{array}{c}\text { Average No. } \\
\text { in each } \\
\text { Household }\end{array}$} & \multirow{2}{*}{$\begin{array}{c}\text { Percentage } \\
\text { in each } \\
\text { Class }\end{array}$} & \multicolumn{5}{|c|}{ Percentages of Age Groups in Each Class and in Whole Practice } \\
\hline & & & & & Under 5 & $5-15$ & 16-39 & $40-64$ & Over 65 \\
\hline $\begin{array}{c}1 \\
2 \\
3 \\
4 \\
5 \\
6 \\
7 \\
\text { Mining }\end{array}$ & $\begin{array}{l}25 \\
26 \\
57 \\
46 \\
87 \\
76 \\
52 \\
99\end{array}$ & $\begin{array}{r}66 \\
76 \\
156 \\
134 \\
265 \\
241 \\
144 \\
344\end{array}$ & $\begin{array}{l}2 \cdot 6 \\
3 \cdot 0 \\
2 \cdot 7 \\
3 \cdot 0 \\
3 \cdot 0 \\
3 \cdot 2 \\
2 \cdot 8 \\
3 \cdot 4\end{array}$ & $\begin{array}{r}4 \cdot 6 \\
5 \cdot 3 \\
10 \cdot 9 \\
9 \cdot 4 \\
18 \cdot 6 \\
16 \cdot 9 \\
10 \cdot 1 \\
24 \cdot 1\end{array}$ & $\begin{array}{r}9 \cdot 1 \\
5 \cdot 3 \\
10 \cdot 2 \\
7 \cdot 5 \\
6 \cdot 8 \\
6 \cdot 6 \\
4 \cdot 9 \\
10 \cdot 7\end{array}$ & $\begin{array}{r}6.0 \\
11.8 \\
10.9 \\
11.9 \\
18.5 \\
17.4 \\
18.7 \\
18.0\end{array}$ & $\begin{array}{l}28 \cdot 8 \\
27.6 \\
29.5 \\
27.6 \\
34.0 \\
35.3 \\
25.7 \\
36.9\end{array}$ & $\begin{array}{l}42 \cdot 4 \\
43 \cdot 4 \\
34 \cdot 0 \\
38 \cdot 1 \\
33 \cdot 2 \\
29 \cdot 9 \\
36 \cdot 8 \\
29 \cdot 6\end{array}$ & $\begin{array}{r}13.7 \\
11.8 \\
15.4 \\
14.9 \\
7.5 \\
10.8 \\
13.9 \\
4.6\end{array}$ \\
\hline All Classes & 468 & 1,426 & $3 \cdot 0$ & & $8 \cdot 0$ & $15 \cdot 8$ & $32 \cdot 4$ & $33 \cdot 7$ & $10 \cdot 1$ \\
\hline
\end{tabular}
PRACTICE POPULATION OF 1,426 PEOPLE

TABLE I

POPULATION AT RISK 
three consultations for each patient who consulted, confirms the impression of heavy demand.

As most surveys have been taken for periods of a whole year, direct reference is not possible but, by allowing for the general seasonal fluctuation in activity in general practice, an approximate idea of the use of the doctor in this practice can be obtained. The overall medical demands of an area are best assessed, for purposes of comparison, by the number of consultations per week, made by a standard number of the registered population or population at risk. The average number of consultations per week per 1,000 registered patients was 123 and this for three winter months with high expected consulting rates.

Table III shows the results of the number of consultations in other practices. The survey of Backett, Heady, and Evans (1954) included "indirect" consultations and is therefore the most convenient for comparison. As the Longlands count was taken in winter, a reasonable guess at the weekly consultations per 1,000 patients over a whole year would be between 100 and 120 . The figure $(73.0)$ given by Brotherston and Chave (1956) refers to a rehoused population of low mean age and hence low expected consulting rates. The other results illustrate the findings of Taylor (1954) of a very wide range of demand for medical services in different areas. Even so, all the published results suggest a high level of demand and Longlands is in the upper half of this scale.

TABLE III

AVERAGE NUMBER OF CONSULTATIONS PER WEEK PER 1,000 PATIENTS REGISTERED IN OTHER SURVEYS WHICH CONTINUED FOR ONE YEAR (Calculated from data in references)

\begin{tabular}{|c|c|c|}
\hline Authors & Date & $\begin{array}{l}\text { Average } \\
\text { per Week }\end{array}$ \\
\hline 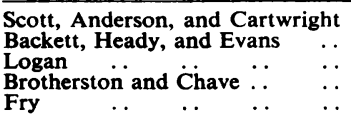 & $\begin{array}{l}1960 \\
1954 \\
1953 \\
1956 \\
1952\end{array}$ & $\begin{array}{c}130 \\
100 \\
\text { Range } 90-57 \cdot 5 \\
73 \\
64\end{array}$ \\
\hline
\end{tabular}

Table IV and the Figure, however, show a gradient of increasing demand from Class I to Class VII and

TABLE IV

HOUSEHOLDS CONSULTING DURING 3 MONTHS BY CLASS

\begin{tabular}{c|cccccccc|c}
\hline Class & I & II & III & IV & V & VI & VII & Mining & Totals \\
\hline $\begin{array}{c}\text { Households } \\
\text { "at Risk" .. }\end{array}$ & 25 & 26 & 57 & 46 & 87 & 76 & 52 & 99 & 468 \\
$\begin{array}{c}\text { Households } \\
\text { Consulting }\end{array}$ & 19 & 20 & 45 & 37 & 76 & 63 & 46 & 91 & 397 \\
\hline $\begin{array}{c}\text { Percentage } \\
\text { Households } \\
\text { Consulting }\end{array}$ & 76 & 78 & 79 & 80 & 87 & 83 & 88 & 92 & 85 \\
\hline
\end{tabular}

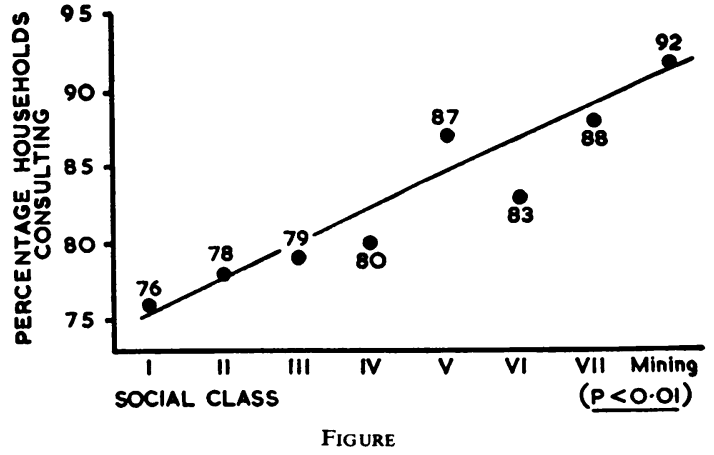

mining, when the percentage of households consulting during 3 months is considered. The rising percentages which are shown graphically were then tested for significance. First the percentage of mining households consulting was found to be significantly higher than households consulting in all other classes at the $\cdot 05$ level. Then the percentage of Class V, VI, VII, and mining households consulting was found to be significantly higher than the percentage of households of Classes I, II, III, and IV (equivalent to Registrar General's Classes I and II) taken together, $P<\cdot 01$.

The number of consultations gives perhaps the most satisfactory picture of total class demands. It can be expressed as a consultation rate. The total number of consultations made by each class has been reduced in Table $\mathrm{V}$ to show the average consultations per patient. Classes I to IV together are again shown to have a lower consultation rate (and lower demand) than the other classes taken together.

The number of patients consulting by class in Table V (overleaf) shows that a greater percentage of patients in Classes V to VII and mining consulted the doctor during the period considered.

Kind of Demand.-Many of the questions the public ask of the lawyer, architect, or doctor will inevitably appear to be very simple to the professional mind. If there is a fee for each service, and the work is arranged on a "piece-work" basis, it might be expected that the man who sells advice would welcome as many clients as possible, no matter how simple were their problems. It is only when a service is provided for the public free or at a nominal charge that the unreasonable request is considered important. If the fire service were run for profit there would be less need to have a system of penalties for improper use. The volume of the demand for medical advice from the National Health Service is so great that many consultations must be for minor ailments. An illness which may be 
TABLE V

NO. OF CONSULTATIONS AND PATIENTS CONSULTING

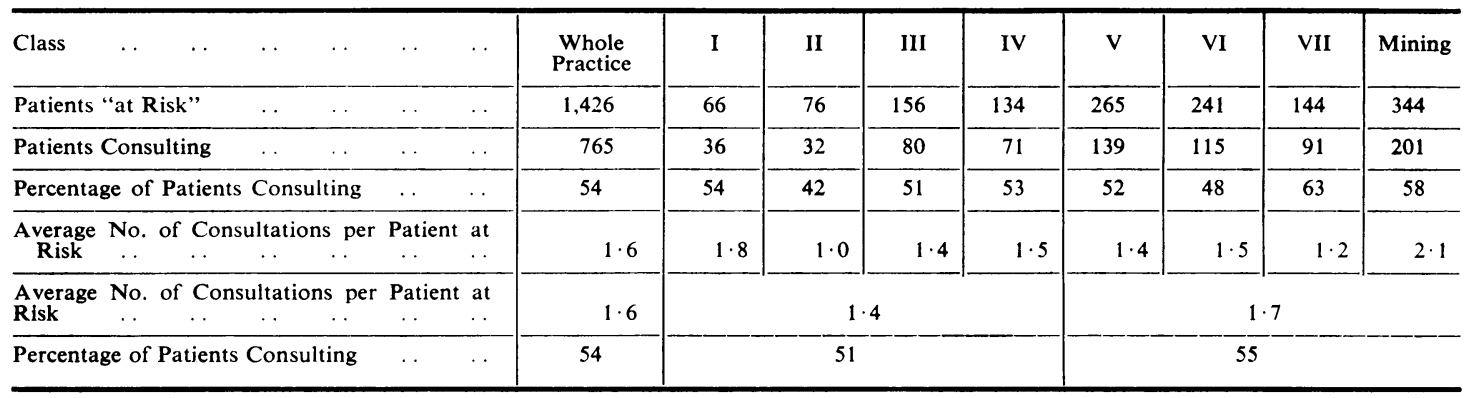

handled easily and confidently by one person without recourse to the doctor may cause another much anxiety. The problem is where to draw the line, and to describe any medical consultation as trivial or unreasonable calls for a subjective assessment by the observer. This problem, in the present setting of general practice, must be approached with caution.

Consultations were labelled trivial in this survey in the following circumstances:

(1) The patient had no disease or only a very minor condition which he was known to be capable of treating himself.

(2) The patient was not anxious about his condition.

(3) The patient showed no evidence of emotional disturbance.

These contacts formed $1 \cdot 3$ per cent. of all consultations. There was no evidence that patients in Longlands consulted unreasonably.

Telephone Consultations (Table VI).--People of all classes use the telephone to ask for home visits but the tendency for people with telephones in their homes or with easy access to one to consult in this way is increasing. There is a very marked class gradient from the 23 per cent. of all consultations for Class I being by telephone to the 1 per cent. in the mining group.

Consultations made Other than at the Surgery (Table VI). - Classes I, II, III, and IV show a preference for non-surgery methods of consulting. In Longlands, the distaste of Class I patients for attending a surgery is well known and the other high figures are in accord. The hypothesis that Classes I, II, III, and IV (Registrar General I and II) make more consultations outside the surgery than with other classes is very highly significant statistically ( $\chi^{2}$ is in the thousands). The attitude is a local tradition but is probably common in other areas, and stems from the idea that to attend a surgery is to lose status. The social stigma arose probably from the association of a doctor's surgery with "panel" patients at a time when there was an allied stigma attached to participation in national pension schemes. Now, even though nearly all Class I patients are National Health and not private patients, the old prejudices continue. The number

TABLE VI

CONSULTATIONS OUTSIDE THE SURGERY

\begin{tabular}{|c|c|c|c|c|c|c|c|c|c|c|c|}
\hline \multicolumn{3}{|c|}{ Consultations other than at the Surgery } & \multirow{2}{*}{\begin{tabular}{|c|}
$\begin{array}{l}\text { Whole } \\
\text { Practice }\end{array}$ \\
910 \\
\end{tabular}} & \multicolumn{7}{|c|}{ Class } & \multirow{2}{*}{$\frac{\text { Mining }}{223}$} \\
\hline \multirow{2}{*}{\multicolumn{2}{|c|}{ Visits and Indirect Requests }} & No. & & $\frac{I}{90}$ & $\frac{\text { II }}{31}$ & $\frac{\text { III }}{123}$ & $\frac{\text { IV }}{128}$ & $\frac{V}{116}$ & $\frac{\text { VI }}{134}$ & $\frac{\text { VII }}{65}$ & \\
\hline & & Percentage of total & 40 & 72 & 40 & 58 & 63 & 31 & 35 & 36 & 30 \\
\hline \multirow{2}{*}{ By Telephone } & \multirow{2}{*}{$\cdots \quad \ldots$} & No. & 99 & 29 & 14 & 18 & 19 & 4 & 4 & 3 & 8 \\
\hline & & Percentage of Total & $4 \cdot 3$ & 23 & 18 & $8 \cdot 5$ & $9 \cdot 3$ & $1 \cdot 1$ & $1 \cdot 0$ & $1 \cdot 6$ & $1 \cdot 0$ \\
\hline \multirow{2}{*}{ Through Chemist } & \multirow{2}{*}{$\begin{array}{ll}. & .\end{array}$} & No. & 113 & 4 & 5 & 31 & 10 & 12 & 24 & 7 & 24 \\
\hline & & Percentage of Total & $4 \cdot 9$ & $3 \cdot 2$ & $6 \cdot 5$ & $14 \cdot 1$ & $4 \cdot 9$ & $\overline{3 \cdot 2}$ & $6 \cdot 3$ & $\overline{1 \cdot 7}$ & $3 \cdot 2$ \\
\hline
\end{tabular}


of home visits is large but, as it is realized that not all contacts can be reasonably expected to take place at home, there is much recourse to the indirect method of consulting.

Class III patients do not show a high rate of telephone consultation but maintain their nonsurgery figures by a very high percentage of requests through the chemist (Table VI) which is more than twice that of any other class.

The population is divided vertically into two sections by way of consulting. Classes I to IV are all reluctant to attend the surgery. Classes $\mathrm{V}$ to VII and mining show little difference in their consulting figures, which indicate that between 60 and 70 per cent. of all their contacts are at the surgery. These classes probably receive the most efficient medical treatment because their demands are more closely in tune with the design of the service. In the consulting room medical records, references, and instruments are to hand and opportunity for investigation is immediate. Ultimately it is the patient who must decide whether or not to present for physical examination and there is evidence that the low rate of surgery attendance for Classes I to IV and the consequent less frequent examination weighs so heavily against efficiency that it is not offset by any pressure which they may exert to see a consultant quickly and privately. Indeed, this very act of seeing a consultant may be rendered ineffective if further reluctance to "fit in with the system" disturbs the liaison between the consultant and general practitioner. Any attitude which gives less opportunity for prompt physical examination and referral to hospital for consultant opinion in doubtful cases, which is necessary if there is to be early diagnosis of organic disease, is dangerous. Table VII, showing the number of patients referred to hospital-low rates for the four classes with low rates of surgery attendance, supports the view that Classes I to IV are at a disadvantage, in spite of other influences such as lower morbidity and occupational diseases (Table VIII).

The request through the chemist (Table VI) is evident as a characteristic of Class III. When this class is omitted from the series of figures for Classes I-IV and compared with those remaining for Classes I, II, and IV, the habit of Class III of making requests in this way more than the others is statistically significant $P<\cdot 001$. A number of patients in nearly all practices approach a chemist of their choice to obtain repeat prescriptions. Before the National Health Service regulations requiring a separate prescription form for each medicine ordered came into force, any prescription could be endorsed with an instruction to the chemist to repeat as necessary.
TABLE VII

NUMBER REFERRED TO HOSPITAL, BY CLASS

\begin{tabular}{|c|c|c|c|}
\hline Class & & I to IV & $\begin{array}{l}\text { V to VII } \\
\text { and Mining }\end{array}$ \\
\hline No. of Hospital referrals $\quad \ldots$ & $\ldots$ & 11 & 50 \\
\hline Percentage of All Consultations & $\cdots$ & $1 \cdot 8$ & $2 \cdot 9$ \\
\hline Percentage of Patients Consulting & $\ldots$ & $5 \cdot 0$ & $9 \cdot 1$ \\
\hline
\end{tabular}

TABLE VIII

OCCUPATIONAL INJURY OR DISEASE, BY CLASS

\begin{tabular}{|c|c|c|c|c|c|c|c|c|c|}
\hline Class & I & II & III & IV & V & VI & VII & Mining & Tota \\
\hline $\begin{array}{l}\text { No. of Consulta- } \\
\text { tions }\end{array}$ & 1 & 0 & 7 & 0 & 6 & 19 & 11 & 48 & 92 \\
\hline $\begin{array}{c}\text { Percentage of All } \\
\text { Consultations }\end{array}$ & \multicolumn{4}{|c|}{$1 \cdot 3$} & \multicolumn{4}{|c|}{$5 \cdot 0$} & $4 \cdot 1$ \\
\hline
\end{tabular}

Since 1948 the practice has continued in a different way. A patient will request the chemist to ask the doctor for a prescription for the necessary medicine which will then be dispensed ready for the patient to purchase later. Patients who are in this category legitimately are, in the main, those suffering from chronic conditions which require frequent treatment but less frequent contact with the doctor. Examples are cases of pernicious anaemia and diabetes mellitus who may only need to be seen every 2 or 3 months.

This method of obtaining medicines is very similar to that of the patient who asks for a prescription to be sent to him by post or the patient who telephones asking the receptionist to have a prescription ready to be collected by him from the surgery. It is, however, not without danger if extended to the treatment of conditions which require closer medical supervision. In Longlands the patients in Class III have probably used this as a means of avoiding attending the surgery as others use the telephone to consult.

\section{SUMMARY}

All consultations in 3 months in a rural general practice were examined for the social class of the patient and the way in which he consulted.

The results showing the heavier demand for consultation in Classes V to VII and Mining support the hypothesis that there is a significant relationship between social class and the frequency of demands made upon the medical services.

The vertical division of the community at the Class IV to V level into two sections on the issue of ways of consulting, makes the hypothesis tenable that there is a relationship between social class and the kind of demand made.

I am grateful to Professor W. J. H. Sprott for his encouragement and support at all stages of this survey. 
REFERENCES

Backett, E. M., Heady, J. A., and Evans, J. C. G. (1954). Brit. med. J., 1, 109.

Brotherston, J. H. F., and Chave, S. P. W. (1956). Brit. J. prev. soc. Med., 10, 200.

Fry, J. (1952). Brit. med. J., 2, 249.

Hall, J., and Jones, D. C. (1950). Brit. J. Sociol., 1, 31.

Kedward, H. B. (1962). J. Coll. gen. Practit., 5, No. 4. In press.

Logan, W. P. D. (1953). Studies on Medical and Popula- tion Subjects, No. 7. General Register Office, H.M.S.O., London.

and Cushion, A. A. (1958). Studies on Medical and Population Subjects, No. 14, Vol. 1, p. 13. H.M.S.O., London.

Scott, R., Anderson, J. A. D., and Cartwright, A. (1960). Brit. med. J., 2, 293.

Taylor, S. (1954). "Good General Practice". Oxford University Press, London. (Nuffield Provincial Hospitals Trust.) 